\title{
Error Management Theory: A New Perspective on Biases in Cross-Sex Mind Reading
}

\author{
Martie G. Haselton and David M. Buss \\ University of Texas at Austin
}

\begin{abstract}
A new theory of cognitive biases, called error management theory (EMT), proposes that psychological mechanisms are designed to be predictably biased when the costs of false-positive and false-negative errors were asymmetrical over evolutionary history. This theory explains known phenomena such as men's overperception of women's sexual intent, and it predicts new biases in social inference such as women's underestimation of men's commitment. In Study $1(N=217)$, the authors documented the commitment underperception effect predicted by EMT. In Study $2(N=289)$, the authors replicated the commitment bias and documented a condition in which men's sexual overperception bias is corrected. Discussion contrasts EMT with the heuristics and biases approach and suggests additional testable hypotheses based on EMT.
\end{abstract}

Several independent traditions of research have documented systematic errors in human judgment and decision making. The most famous of these was established by Tversky and Kahneman, 1974) and is influential in cognitive and social psychology as well as in business and economics (Lopes, 1991). Social cognition researchers in this tradition have documented cognitive errors such as base-rate neglect, confirmation bias, and illusory correlation (Nisbett \& Ross, 1980). Typically the goal in these studies was to identify biased heuristics---"rules of thumb" or "shortcuts"-that are the hypothesized source of errors (Tversky \& Kahneman, 1974). A second line of research concerns a particular domain of judgment: inferences about the thoughts and intentions of members of the opposite sex. A potentially harmful error is that men appear to over-infer sexual intent in women in response to cues such as a smile or friendliness (see, e.g., Abbey, 1982, 1991). These errors have typically been attributed to sex-role socialization rather than to the operation of simplifying heuristics.

These two lines of research are related in that they concem judgment under uncertainty. Judging the likelihood of probabilistic events, such as in tasks used in heuristics and biases research, requires judgment under uncertainty. Similarly, inferences about the sexual intentions of others, which are not directly observable, are based on probabilistic cues and hence also uncertain.

Martie G. Haselton and David M. Buss, Department of Psychology, University of Texas at Austin.

We are greatly indebted to $W$. Todd DeKay, whose initial insights led to the formulation of error management theory. For discussions and commentary on the ideas contained in this article we thank April Bleske, Ryan Brown, Randy Diehl, and Lee Kirkpatrick. We thank Amy Isaia, Lisa Moliski, Jennifer Semmelroth, Todd Shackelford, and Lars Strother for help collecting and preparing portions of the data for analysis. We thank Pat Randall and Tor Neilands for helpful suggestions on statistical analysis and presentation.

Correspondence concerning this article should be addressed to Martie $G$. Haselton, Department of Psychology, University of Texas, Mezes Hall 330, Austin, Texas 78712. Electronic mail may be sent to haselton@ psy.utexas.edu.
This article describes two hypotheses about cross-sex mindreading biases, one that explains men's overperception of women's sexual intent and one that predicts a new error. These hypotheses are derived from a theory of errors that challenges the position that errors reflect shortcomings or limitations of psychological design (see, e.g., Kahneman, Slovic, \& Tversky, 1982; Nisbett \& Ross, 1980 ) or susceptibility to erroneous social messages caused by socialization. This new theory proposes that cognitive errors result from adaptive biases that exist in the present because they led to survival and reproductive advantages for humans in the past.

\section{Error Management Theory}

When judgments are made under uncertainty, two general types of errors are possible-false positives (Type I errors) and false negatives (Type II errors). A decision maker cannot simultaneously minimize both errors because decreasing the likelihood of one error necessarily increases the likelihood of the other (Green \& Swets, 1966).

The costs of these two types of errors are rarely symmetrical. In scientific hypothesis testing, Type I errors are usually considered more costly than Type II errors. Scientists, therefore, typically bias their decision-making systems (e.g., inferential statistics) toward making Type II errors. Errors are also asymmetrical in warning devices like fire alarms, which are biased in the opposite direction. Missed detections (Type II errors) are more costly; therefore, the bias is toward making false alarms (Type I errors). Whenever the costs of errors are asymmetrical, humanly engineered systems should be built to be biased toward making less costly errors (Green \& Swets, 1966). This bias might increase overall error rates, but it minimizes overall cost.

According to error management theory (EMT; Haselton, Buss, \& DeKay, 1998), decision-making adaptations have evolved through natural or sexual selection to commit predictable errors. Whenever there exists a recurrent cost asymmetry between two types of errors over the period of time in which selection fashions adaptations, they should be biased toward committing errors that are less costly. Because it is exceedingly unlikely that the two 
types of errors are ever identical in the recurrent costs associated with them, EMT predicts that human psychology will contain decision rules biased toward committing one type of error over another (also see Cosmides \& Tooby, 1996; Nesse \& Williams, 1998; Schlager, 1995; Searcy \& Brenowitz, 1988; Tomarken, Mineka, \& Cook, 1989).

The logic of EMT extends to benefit asymmetries as well as to cost asymmetries. Consider two types of correct inferences, hits and correct rejections. If the benefits associated with these two different correct inferences differ recurrently over evolutionary time, other things being equal, then selection will favor the reasoning strategy that is biased toward the more beneficial inference, even if it results in more errors overall. In cases where the costs of the two different errors are the same, but the benefits are asymmetrical, the benefit asymmetry will be the driving selective force. In cases where the benefits of correct inferences are the same but the costs of errors are asymmetrical, the cost asymmetry will be the driving selective force. The key point of EMT is that selection will favor biased decision rules that produce more beneficial or less costly outcomes (relative to alternative decision rules), even if those biased rules produce more frequent errors. In this article we apply the logic of EMT to two social adaptive problems: inferences about sexual interest and commitment intent.

\section{Sex Differences in Reading Sexual Intent}

In the early 1980s, Abbey launched a tradition of research into sex differences in sexual perceptions. In Abbey's (1982) pioneering study, unacquainted male-female dyads participated in a short discussion while a hidden man and woman observed the interaction through one-way glass. The observers rated the degree to which the target individuals' behaviors indicated their sexual intentions and estimated the target individuals' sexual attraction to one another. The targets provided parallel self-ratings and ratings of their conversation partner. The men in the study perceived greater sexual intent in women than did the women.

Men's greater inference of women's sexual intent has been replicated in laboratory studies similar to the original study (e.g., Saal, Johnson, \& Weber, 1989), studies using photographs (e.g., Abbey \& Melby, 1986), videos (e.g., Johnson, Stockdale, \& Saal, 1991), and short vignettes (e.g., Abbey \& Harnish, 1995). In these studies male and female targets were depicted in sexually ambiguous circumstances and third-party perceivers rated the sexual intent of the depicted men and women.

\section{Are Men Misreading Women's Actual Intent?}

There is no direct gauge of intentions analogous to a thermometer for measuring temperature. Researchers must rely on indirect measures of mental states. Two commonly used indirect measures are (a) reports from the target whose intentions are read (see, e.g., Ickes, 1997) and (b) reports from other knowledgeable sources, such as same-sex third-party perceivers (see, e.g., Abbey, 1982).

Both of these types of ratings may be biased. Self-ratings are susceptible to self-enhancement biases (e.g., Sedikides, 1993). Women's self-ratings, for example, may underestimate their true sexual intent (Einon, 1994) because signals of sexual promiscuity may cause reputational damage (Buss, 1994; Einon, 1994). Thirdparty women's ratings may be biased in the opposite direction, as in derogation of same-sex competitors (Buss \& Dedden, 1990; Schmitt \& Buss, 1996). The same enhancement and derogation counterbiases may also exist in men's self-ratings and their ratings of other men. Men may under-rate their true sexual intent in order to highlight other intentions, such as intentions of commitment and love (Schmitt \& Buss, 1996), which are desired by women (Buss, 1994). Men, like women, derogate their same-sex competitors" sexual fidelity and long-term romantic intentions (Buss \& Dedden, 1990; Schmitt \& Buss, 1996), resulting in potentially inflated third-party sexual intent ratings provided by men.

If this reasoning is correct, the true state of women's sexual intent should be bracketed by women's self-ratings and the ratings provided by third-party women. One standard for evaluating whether men enr is therefore to evaluate cross-sex perceptions relative to self-perceptions and third-party women's ratings. When men's perceptions exceed or underestimate both women's selfperceptions and third-party women's perceptions, men may be in error. Similarly, evidence of a possible error in women's cross-sex perceptions would occur if their perceptions simultaneously exceed (or underestimate) both men's self-perceptions and thirdparty men's perceptions. Past studies have failed to compare these three ratings separately (e.g., Abbey, 1982).

\section{Why Do Men and Women Perceive Women's Sexual Intent Differently?}

Researchers have developed several hypotheses about men's apparent overperception of women's sexual intent. The first is the general oversexualization hypothesis: Because men tend to rate women's and men's sexual intent more highly than do women, men appear to "oversexualize the world" (see, e.g., Abbey, 1982, 1991). According to this hypothesis, men do this because they are socialized to be sexual, whereas women are socialized to be coy (Abbey, 1982, 1991). The second is the media hypothesis (Abbey, 1991): Men are exposed to leading media images depicting women as initially coy but then overcome with sexual desire. The third is the default-model hypothesis, which is closely related to the false consensus model in social-cognitive research (see Marks \& Miller, 1987, for a review). This hypothesis suggests that men exceed women in sexual desire and use their own desires as an erroneous gauge of women's desires (Shotland \& Craig, 1988). A weakness shared by these hypotheses is that they have been offered post hoc and have not yet been supported with independent tests or novel predictions based on their premises.

\section{Hypotheses About Cross-Sex Mind-Reading Biases}

We applied EMT to the domain of cross-sex mind reading. EMT offers a new explanation for men's sexual overperception and predicts a new bias in mind reading.

Hypothesis 1: Sexual overperception bias. Men possess intentionreading adaptations designed to minimize the cost of missed sexual opportunities by overinferring women's sexual intent.

One primary factor limiting men's reproductive success over evolutionary history was their ability to gain sexual access to fertile women (Symons, 1979). Ancestral men who tended to falsely infer a prospective mate's sexual intent (a false-positive error) paid the fairly low costs of failed sexual pursuit: perhaps some lost time 
and wasted courtship effort. In contrast, men who tended to falsely infer that a woman lacked sexual intent (a false-negative error) paid the costs of losing a sexual opportunity and hence a reproductive opportunity. In the currency of natural selection-the replicative success of one design relative to other designs (Dawkins, 1989) - the latter error was more costly.

Hypothesis 2: Commitment-skepticism bias. Women possess intention-reading adaptations designed to minimize the cost of feigned commitment by men by underinferring men's commitment intent.

Using EMT logic, we hypothesized that women's inferences of men's commitment intent would show a reverse bias. For women, the costs of falsely inferring a prospective mate's commitment when little or none exists (a false positive error), according to this hypothesis, were greater than the costs of failing to infer commitment that does exist (a false negative error). An ancestral woman who consented to sex with a man who abandoned her shortly thereafter because of his low level of commitment could have suffered the costs of an unwanted or untimely pregnancy, raising a child without an investing mate, a reduction in her mate value, and reputational damage (Buss, 1994). These were substantial costs given the lowered survival of the child and impairment of future reproductive potential (Hurtado \& Hill, 1992). An ancestral woman who erred by underestimating a man's commitment, in contrast, may have merely evoked more numerous and more frequent displays of commitment by the man who truly was committed (Buss, 1994). Given the tremendous importance to women of securing a committed mate, according to this hypothesis, modern women are descendants of ancestral mothers who erred in the direction of being cautious-a commitment-skepticism bias.

These hypotheses require the assumption that men and women, over the course of human evolutionary history, were able to exercise some degree of individual choice in entering or leaving mateships. All available cross-cultural and anthropological evidence supports this assumption (Buss, 1994). Most cultures permit individuals to exercise choice, either directly or indirectly. Even in cultures where marriages are arranged by elders, individuals manage to influence their parents' choices, sometimes refuse to marry a designated partner, sometimes elope with a loved one against parents' wishes, and sometimes marry one person while having sex with a lover of choice (Buss, 1994; Jankowiak, 1995). Similarly, choice can be exercised through divorce or abandonment, patterns observed in every known culture (Betzig, 1989; Buss, 1994).

Hypothesis 3: The sister correction. Men possess intention-reading adaptations designed to correctly read their sisters' sexual intentions.

EMT proposes that cost asymmetries lead to the evolution of biased inferential mechanisms. When the specific targets of crosssex mind reading vary, however, cost asymmetries vary, and the bias when mind reading one target should shift accordingly. Hypothesis 1 proposed that the costs to men of missing a sexual opportunity were greater than the costs of failed pursuit, causing misperceptions of sexual intent. But what happens when the target represents a class of individuals who are not reproductively appropriate sex partners, such as sisters?

From an evolutionary perspective, ancestral men and their sisters had a large degree of shared fate. Differential gene replication could occur either directly through individual reproduction or indirectly if individuals aided the reproduction of their close genetic relatives who were likely to possess the gene (Hamilton, 1964). Men who recognized their sisters' upset when their intentions were misread (perhaps if she were the victim of unwanted sexual advances or attempted rape) may have been better able to protect their sisters' ability to exercise choice in mating and preserve their sisters' reputations. In contrast, men who extended their overinference of sexual intent to all targets, including sisters, would have failed to protect the interests of their kin. If men's over-perception of women's sexual intent is indeed an error designed to minimize the likelihood of missed sexual opportunities, sisters would have been inappropriate targets of these inferences. We hypothesized that men "correct" their biased inferences about women's sexual intent when the target is a sister.

\section{Study 1: Do Women Underperceive Men's Commitment Intent?}

To test the commitment-skepticism hypothesis we compared cross-sex perceptions of commitment intent with same-sex perceptions of commitment intent. Because the commitment-intent items were worded in the direction of noncommitment (e.g., "he will avoid getting committed..."), the prediction derived from the hypothesis was that women's ratings would exceed the criterion measure: men's perceptions of other men. We also examined perceptions of sexual intent. We predicted that men's ratings of women's sexual intent would exceed women's ratings.

\section{Method}

\section{Participants}

The participants were 217 undergraduates, 113 men and 104 women. Participation partially fulfilled a course requirement. The average age was 18.56 for men and 18.64 for women.

\section{Materials}

The instructions were "Please rate the following statements on whether or not you agree with them or disagree with them. Use the following 7-point scale." The scale ranged from 1 (strongly disagree) to 4 (neutral) to 7 (strongly agree). Items pertaining to men's commitment and women's commitment appeared on the same page but were interspersed between items assessing other aspects of relationships (such as the frequency with which men and women discuss their relationships). The items appeared in the same order for all participants. The items about men appeared before the items about women. Three items assessed perceptions of commitment: (a) "Men [women] tend to be afraid of long-term commitments such as marriage"; (b) "Men [women] tend to keep their emotions to themselves in order to avoid making a commitment to a woman [man]"; (c) "As long as a man [woman] can have lots of sex without commitment, he [she] will avoid getting committed to one woman [man]."

Items pertaining to sexual intent appeared in the same order (perceptions of men first) but on different pages. The instructions were "To what extent do the following behaviors indicate 'sexual interest' on the part of a man [woman]?" Each behavior was rated on a 7-point rating scale ranging from 1 (no sexual interest) to 4 (moderate sexual interest) to 7 (a lot of sexual interest). Eight behaviors were presented: “. . . on the first day of work, approaching a male [female] co-worker, smiling brightly, and striking up a friendly conversation"; “. . . smiling at a man [woman] at a party"; "... being friendly to a man [woman] she [he] just met at the party"; 
"... touching a man [woman] on the arm at the party"; ". . reducing the distance between her [him] and a man [woman] to a few inches at the party"; ". . . prolonged eye contact with the woman [man] he [she] just met at the party"; ". . going to a bar alone"; and "... dancing provocatively with a woman [man] he [she] just met at the party."

\section{Procedure}

Participants completed the questionnaire in small same-sex groups. A same-sex researcher was present to answer questions.

\section{Results}

A commitment composite was created by computing the arithmetic mean of the ratings provided for the three commitment items ( $\alpha=.74$ and $\alpha=.62$ for perceptions of men and women, respectively). A mixed-model $2 \times 2$ analysis of variance (ANOVA), with sex of rater and sex of target as between- and within-group factors, revealed a significant interaction, $F(1$, $213)=14.87, p<.001$, suggesting that the pattern of ratings of the target (same sex vs. opposite sex) differed for men and women raters.

Two Bonferroni-corrected planned contrasts ( $\alpha=.025$ for each pair of contrasts) compared men's and women's ratings of each target. As predicted by the commitment-skepticism hypothesis, women's ratings of men's commitment avoidance $(M=4.52$, $S D=1.19$ ) were significantly greater than men's ratings of men's commitment avoidance $(M=3.96, S D=1.31), F(1$, $213)=10.63, p<.01$. We did not predict a difference between men's ratings of women's commitment and women's selfperceived commitment, and none were found (for men, $M=2.90$, $S D=1.11$; for women, $M=2.69, S D=0.97), F(1,213)=2.22$, $p=.14$.

A sexual-intent composite was created by computing the arithmetic mean of the ratings provided for the eight sexual-intent items ( $\alpha=.84$ and $\alpha=.82$ for perceptions of men and women, respectively). A mixed-model $2 \times 2$ ANOVA was conducted with sex of rater and sex of target as between- and within-group factors. There was neither a significant interaction of the factors nor a main effect of sex of target ( $p s>90$ ). There was a significant main effect of rater, with men's ratings $(M=3.70, S D=0.85)$ exceeding women's ratings $(M=3.39, S D=0.88), F(1,211)=6.73$, $p=.01$.

\section{Discussion}

Using error management theory, we hypothesized that women underperceive men's commitment. Our prediction derived from this hypothesis that women would overperceive men's commitment avoidance was confirmed. In contrast to the sex difference in perceptions of men's commitment, there were no significant sex differences in perceptions of women's commitment. This suggests that commitment underperception is specific to women's cross-sex perceptions and does not occur in men's cross-sex perceptions.

We predicted and found that men perceive greater sexual intent in women; however, as in past studies, men's perceptions of men's sexual intent were also greater than women's perceptions of men's intent. This may indicate that women underperceive men's sexual intent or that men's overperception extends to targets of both sexes. In Study 2, we attempted to resolve this ambiguity by examining an additional criterion measure of men's sexual intent.

Study 1 had several important limitations. First, the questions about men's sexual intent and commitment appeared before the questions about women. It is therefore possible that the results were affected by item order. Second, the commitment items were all "commitment avoidance" items, which may have been somewhat leading.

\section{Study 2}

Study 2 consisted of two parts. In Part 1, we assessed cross-sex perceptions relative to self-report criterion measures. In Part 2, we assessed cross-sex perceptions relative to same-sex and self-report criterion measures. Our first goal in Study 2 was to replicate the new finding in Study 1. Our second goal was to eliminate the two potential threats to validity in Study 1 by counterbalancing the order in which participants were asked about men and women targets and by asking participants nonleading questions about commitment. Our third goal was to assess cross-sex perceptions relative to an additional criterion measure: self-perceptions. This criterion measure allowed further investigation of women's perceptions of men's sexual intent. Collecting same-sex, cross-sex, and self-perceptions in Study 2 also allowed us to test the default model hypothesis, which proposes that men's overperception of women's sexual intent is a result of an erroneous extension of self-perceptions to others. Our fourth goal was to test Hypothesis 3: the sister correction.

\section{Specific Predictions}

\section{Predicted Mind Reading Biases}

In Part 1 of this study, men's and women's self-perceptions were the criterion measures. We predicted that men's ratings of women's sexual intent would exceed women's self-perceived sexual intent and that women's ratings of men's commitment intent would be lower than men's self-perceived commitment intent.

In Part 2 of this study, there were two criterion measures: same-sex perceptions and self-perceptions. We predicted that men's ratings of women's sexual intent would exceed the criterion measures, whereas women's ratings of men's commitment would be lower than the criterion measures.

\section{The Predicted Correction for Sisters}

Hypothesis 3 proposed that men's overperception of women's sexual intent will not occur when the mind-reading target is a sister. This hypothesis predicts that men's perceptions of a sister's sexual intent will be lower than men's perceptions of unrelated women's sexual intent.

\section{Method}

\section{Participants}

The participants were 289 undergraduate students, 168 women and 121 men. The average age of the women was 19.14 , and the average age of the men was 19.25 . Their participation partially fulfilled a research requirement for a psychology course. 


\section{Materials}

Sex and commitment contrast instrument. Participants completed two forms of the sex and commitment contrast instrument. The order was counterbalanced. On one they reported their own likely intentions given that they engaged in each of 15 different behaviors. On the other form, they reported analogous perceptions of the intentions of members of the opposite sex. The instructions for women's cross-sex perception form were

Imagine a man you might date. Imagine that you had been out on a few casual dates with him and you had not had sex with him. Imagine that he engaged in each of the acts listed below. For each act, make two ratings: (1) Rate the man's interest in having sex with you, given that he engaged in that act. (2) Rate the man's interest in developing a committed relationship with you, given that he engaged in that act."

The instructions for the women's self-report form were

Imagine a man you might date. Imagine that you had been out on a few casual dates with him and you had not had sex with him. Imagine engaging in each act listed below. For each act, make two ratings: (1) Rate how likely it would be that you would want to have sex with the man, given that you engaged in that act. (2) Rate how likely it would be that you would be interested in developing a committed relationship with the man, given that you engaged in that act.

The rating scale had seven anchored points $(-3=$ extremely unlikely, $-2=$ moderately unlikely, $-1=$ somewhat unlikely, $0=$ neutral, $+1=$ somewhat likely, $+2=$ moderately likely, and $+3=$ extremely likely). The scale was followed by 15 cues in the form, "If he did X he [she] would want ..." (cross-sex form) or "If I did X, I would want ..." (self-report form), where $X$ represents each of 15 different cues. Representative examples of the cues are "held hands with me [him/her]"; "complimented me [him/her] on my [his/her] appearance"; "passionately kissed me [him/ her]"; "told me [him/her] that he [she/I] loved me [him/her]"; "bought me [him/her] expensive jewelry." To the right of each cue were spaces in which to rate how much the cue indicated (a) sexual intent and (b) commitment intent.

Cross-sex perception instrument. Participants completed three forms: a same-sex, an opposite-sex, and a self-perception form. The order of the forms was randornized across participants. Each of the six possible orders of forms was administered to approximately equal numbers of men and women participants.

The rating scale had seven anchored points $(-3=$ strongly disagree, $-\mathbf{2}=$ moderately disagree, $-1=$ somewhat disagree, $0=$ neutral, $+\mathrm{i}=$ somewhat agree, $+2=$ moderately agree, and $+3=$ strongly agree). It was followed by 24 items, 5 of which were designed to test the commitment-skepticism hypothesis (the remaining items assessed perceptions not related to our hypotheses, such as perceptions of concern with social status and physical appearance). These items were (a) "If a man [woman] could have lots of sex without commitment, he [she] would avoid getting committed to one woman [man]"; (b) "Most men [women] prefer many different sex partners over one committed sex partner"; (c) "A typical man [woman] needs to know that a woman [man] loves him [her] before he [she] is willing to have sex with her [him]"; (d) "In order for a typical man [woman] to feel comfortable having sex with a woman [man], he [she] needs to know that she [he] feels committed to him [her]"; and (e) "Men [women] tend to avoid long-term commitments like marriage."

Following these items was a depiction of the 7-point extremely unlikelyextremely likely scale used in the sex and commitment contrast questionnaire (see above). This scale was followed by four items designed to test the sexual overperception hypothesis (Hypothesis 1): (a) "At a party, if a man [woman] smiles at a woman [man] repeatedly over the course of the evening, what is the likelihood that he [she] wants to have sex with her [him]?"; (b) "When a man [woman] touches a woman's [man's] arm when he [she] is out on a date with her [him], how likely is it that he [she] is interested in having sex with her [him]?"; (c) "When a man [woman] goes out to a bar, how likely is it that he [she] is interested in finding someone to have sex with that night?"; and (d) "In class, if a man [woman] smiles at a female [male] student repeatedly over the course of the lecture, what is the likelihood that he [she] wants to have sex with her [him]?" Selfperception items contained appropriate pronoun substitutions; for example: "If I could have lots of sex without commitment, I would avoid getting committed to one woman [man]."

Cross-sex sibling perception instrument. The instructions for the cross-sex sibling perception instrument were

The following questions are about a member of your family. Please think about your sister [brother]. If you have more than one, think of the one who is closest to you in age. Answer the following questions about this person.

These instructions were followed by a short biographical information section requesting the sibling's initials, age, degree of relationship (full biological sibling, adopted, etc.), and the number of years the participant and the sibling lived in the same household. The siblings' initials were requested in an effort to "commit" the participant to answering the questions about only one specific sibling and to help the participant think more vividly about this person.

Following the 7-point extremely unlikely-extremely likely scale was a subset of the items from the cross-sex perception questionnaire. These items were (a) "At a party, if your sister [brother] smiles at a man [woman] repeatedly over the course of the evening, what is the likelihood that she [he] wants to have sex with him [her]?"; (b) "If your sister [brother] touches a man's [woman's] arm when they are out on a date, how likely is it that she [he] is interested in having sex with him [her]?"; and (c) "If your sister [brother] goes out to a bar, how likely is it that she [he] is interested in finding someone to have sex with that night?"

\section{Procedure}

Participants were tested in same-sex groups of 20 individuals or fewer. The same-sex researcher conducting the sessions was available to answer questions. Participants with cross-sex siblings completed the sibling instrument after completing the other questionnaires.

\section{Data Analysis}

We created composite ratings by calculating the arithmetic mean of the sexual intent items within each instrument and by calculating the arithmetic mean of the commitment intent items within each instrument. To confirm that the pattern of target ratings differed systematically for each sex, we first conducted a mixed-model factorial ANOVA for each dependent variable. Sex of rater and target type (e.g., cross-sex vs. self-report) were within- and between-groups factors, respectively. We followed this analysis with Bonferroni-corrected planned contrasts ( $\alpha=.025$ for each pair of contrasts) designed to assess differences between men's and women's cross-sex ratings and the criterion measures. ${ }^{1}$

\section{Results: Sex and Commitment Contrast}

\section{Commitment Intent}

Reliabilities ( $\alpha \mathrm{s}$ ) for composites were .88 for ratings of men and .86 for ratings of women. As in Study 1, a significant rater by

\footnotetext{
${ }^{1}$ The three commitment-avoidance items in the cross-sex perception instrument were reverse-scored before creating the composite. All contrasts were conducted using local error terms. Contrasts designed to test a priori predictions were one-tailed tests; contrasts assessing differences for which there were no a priori predictions were two-tailed.
} 
target interaction, $F(1,273)=30.10, p<.001$, suggested that the pattern of target ratings differed for male and female raters.

As predicted by the commitment-skepticism hypothesis, women's perceptions of men's commitment intent as indicated by the men's display of the 15 dating cues $(M=1.21, S D=0.74)$ were significantly lower than men's perception of their own commitment intent given their display of the cues $(M=1.65, S D=0.50)$, $F(1,279)=31.58, p<.001$. Men's perception of women's commitment intent as indicated by the women's display of the 15 dating cues $(M=1.65, S D=0.48$ ) was not significantly different from women's perception of their own commitment intent given their display of the cues $(M=1.60, S D=0.76), F(1,276)=.44$, $p=.51)$.

\section{Sexual Intent}

Reliabilities for the composites were .95 for ratings of men and .96 for ratings of women. There was a significant rater by target interaction, $F(1,265)=80.33, p<.001$, indicating that the pattern of target ratings differed for men and women raters.

As predicted by Hypothesis 1 and as documented in past studies, men's ratings of women's sexual intent as indicated by women's display of dating cues were greater $(M=1.02, S D=0.90)$ than women's self-perceived sexual intent given the cues $(M=0.13$, $S D=1.60), F(1,270)=28.84, p<.001$. Women's ratings of men's sexual intent as indicated by the men's display of dating cues $(M=1.42, S D=1.00)$ were greater than men's selfperceived sexual intent given the cues $(M=1.10, S D=1.23), F(1$, $273)=2.40, p=.02$, though to a lesser degree. This result contradicts the hypothesis that men's perceptions are generally oversexualized, because women's ratings exceeded men's ratings.

\section{Results: Cross-Sex Perception}

\section{Commitment Intent}

Reliabilities of the composites were $.74, .70$, and .83 for perceptions of men, women, and self, respectively. A significant rater by target interaction, $F(2,566)=104.70, p<.001$, indicated that the rating pattern differed for men and women raters.

As predicted, women's ratings of men's commitment intent $(M=-1.27, S D=1.10)$ were significantly lower than men's perceptions of other men's commitment intent $(M=-0.99$, $S D=1.02), F(1,281)=4.80, p<.02$, and men's self-perceived commitment intent $(M=0.55, S D=1.35), F(1,281)=156.25$, $p<.001$. These results confirm the predictions derived from Hypothesis 2.

We did not have a priori predictions about differences between men's perceptions of women's commitment intent and the criterion measures. Men's and women's perceptions of women's commitment intent $(M=1.29, S D=0.87$, and $M=1.17, S D=1.00$, respectively) did not differ significantly, $F(1,281)=1.17, p=$ .28 , but men's perceptions were significantly lower than women's self-perceived commitment intent $(M=2.04, S D=1.03), F(1$, 281) $=41.86, p<.01$.

Figure 1 summarizes these findings. The data presented in the left panel test Hypothesis 2-women's perceptions of men's commitment. The right panel depicts data for men's perceptions of women's commitment. For ratings of men and women separately, composite cross-sex ratings are contrasted with each of the criterion measures. Evidence of a possible cross-sex mindreading error exists when cross-sex perceptions exceed or underestimate both criterion measures. This occurred for women's perceptions of men's commitment intent, which were significantly lower than each criterion measure (the predicted effects),

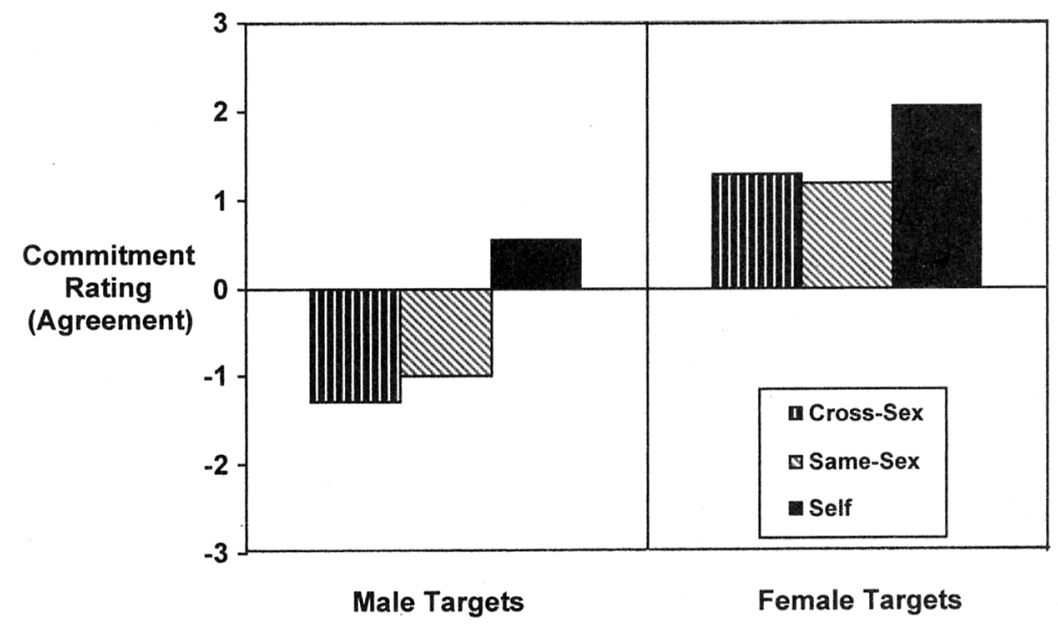

Figure 1. Women's perception of men's commitment appears in the left panel. Cross-sex perceptions represent women's perceptions of men and men's perceptions of women. Same-sex and self-perception ratings are the criterion measures. Evidence of a possible cross-sex mind-reading error is obtained if the cross-sex perception significantly exceeds or underestimates both criterion measures, as is the case for women's perception of men's commitment (left panel). This effect suggests that women underperceive men's commitment intent, as predicted by Hypothesis 2. Men's perception of women's commitment fell between the two criterion measures (right panel), suggesting the possibility that men accurately perceive women's commitment. 


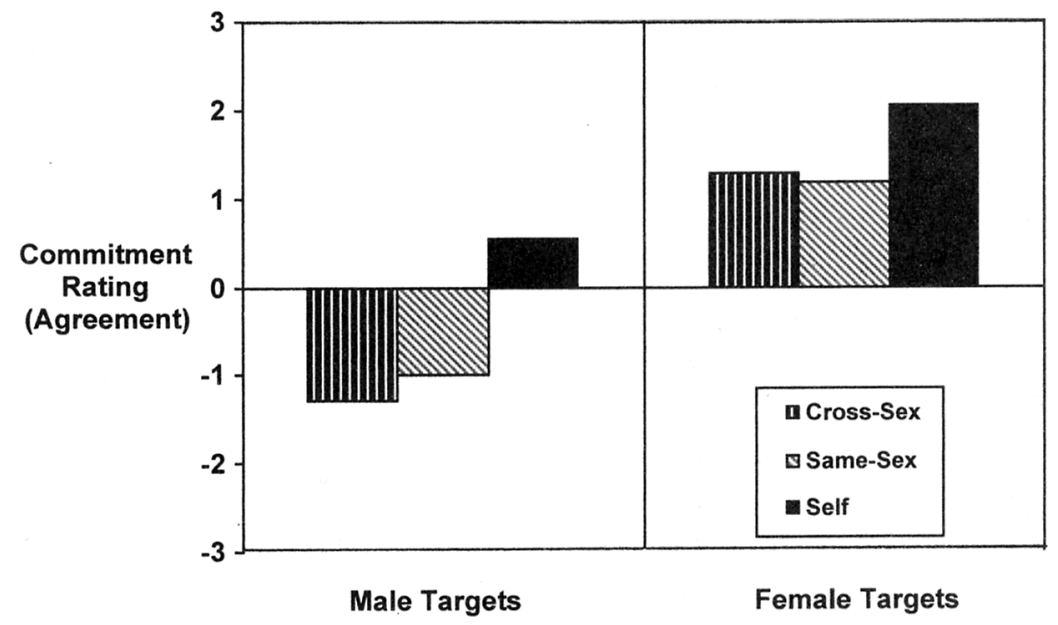

Figure 2. Men's perception of women's sexual intent appears in the left panel. Cross-sex perceptions represent men's perceptions of women and women's perceptions of men. Same-sex and self-perception ratings are criterion measures. Evidence of a possible cross-sex mind-reading error is obtained if the cross-sex perception significantly exceeds or underestimates both criterion measures. This is the case for men's perception of women's sexual intent (left panel). Women's perception of men's sexual intent fell between the two criterion measures (right panel), suggesting the possibility that women accurately perceive men's sexual intent.

but not for men's perceptions of women's commitment. Men's perceptions fell between the two criterion measures, suggesting that men may correctly infer women's commitment.

\section{Sexual Intent}

Composite reliabilities were $.83, .83$, and .91 for perceptions of men, women, and self, respectively. A significant rater by target interaction, $F(2,566)=104.70, p<.001$, confirmed that the pattern of target ratings differed for men and women raters.

As predicted, men's ratings of women's sexual intent $(M=0.12, S D=1.01$ ) were significantly greater than women's ratings of women $(M=-0.34, S D=1.19), F(1,283)=11.70$, $p<.01$, and significantly greater than women's self-perceived sexual intent $(M=-1.69, S D=1.38), F(1,283)=136.89, p<$ .001 . These results confirm the predictions derived from Hypothesis 1.

Women's perceptions of men's sexual intent were between the two criterion measures. Women's perceptions of men's sexual intent $(M=1.01, S D=1.02)$ were significantly lower than men's perceptions of other men's sexual intent $(M=1.29, S D=1.04)$, $F(1,283)=4.97 ; p<.05$, but significantly greater than men's self-perceived sexual intent $(M=0.54, S D=1.34), F(1$, 283) $=11.63, p<.01$.

Figure 2 summarizes these findings. The left panel depicts results testing Hypothesis 1-men's perceptions of women's sexual intent. The right panel depicts women's perceptions of men's sexual intent. Men's perceptions of women significantly exceeded each of the criterion measures (left panel), providing evidence of a potential cross-sex mindreading error. Women's perceptions of men were between the criterion measures (right panel), suggesting potentially accurate perceptions.

\section{Results: Cross-Sex Sibling Inferences}

One hundred sixty-eight participants completed cross-sex sibling instruments (69 men and 99 women). Average sibling age was 20.57 (ranging from 6 to 36 years). Most siblings were full biological siblings $(85 \%)$. The analysis was limited to full siblings and to siblings who were at least 15 years old. ${ }^{2}$ There were 131 eligible participants ( 72 women and 59 men) using these criteria. The average age of the women's brothers was 20.42 (ranging from 15 to 31 ) and the average age of men's sisters was 21.49 (ranging from 15 to 31 ).

Reliability of the sibling composite was .87 . A significant rater by target (cross-sex other vs. cross-sex sibling) interaction, $F(1,127)=8.89, p<.01$, indicated that the pattern of differences across target ratings differed for men and women raters.

As predicted, men's perceptions of their sisters' sexual intent $(M=-1.03, S D=1.44)$ were significantly lower than their perceptions of other women's sexual intent $(M=.02, S D=1.09)$, $F(1,57)=23.62, p<.001$. This confirms the prediction that men would perceive less sexual intent in sisters than in unrelated

\footnotetext{
${ }^{2}$ The analysis was limited to full biological siblings because the hypotheses pertained most directly to full biological siblings. The analysis was limited to siblings 15 years old or older because at this age most individuals have reached puberty and questions about sexual and commitment intent become relevant to them. Analysis using all siblings did not significantly alter the results.
} 
women. ${ }^{3}$ Men's perceptions of their sisters fell between the two criterion measures (composite ratings of women's perceptions of women and women's self-perceptions for the three items appearing on the sibling form). Men's perceptions of sisters were lower than women's perceptions of women's sexual intent $(\mathbf{M}=-0.21$, $S D=1.19), F(1,223)=18.15, p<.001$, and greater than women's self-perceived sexual intent $(M=-1.69, S D=1.39)$, $F(1,222)=10.00, p<.01$.

We did not have an a priori prediction about women's perception of their brother's sexual intent. We found that women's perceptions of their brothers' sexual intent $(M=-0.50$, $S D=1.69$ ) were also significantly lower than women's perceptions of other men's sexual intent $(M=1.37, S D=0.87), F(1$, $70)=111.94, p<.001$. Women's perceptions of their brothers' sexual intent fell below each criterion measure. Women's ratings of brothers were lower than men's ratings of. men $(M=1.37$, $S D=1.00), F(1,189)=92.74, p<.001$, and lower than men's self-ratings $(M=0.47, S D=1.37), F(1,189)=18.92, p<.001$.

\section{Discussion}

Each part of Study 2 built on Study 1 by eliminating two potential threats to validity in Study 1: order effects and leading questions. Because Study 2 replicated the effects observed in Study 1, the findings in Study 1 cannot be attributed to these threats to validity.

\section{Predicted Mind-Reading Biases}

The predictions derived from Hypotheses 1 and 2 were confirmed in each part of Study 2. In Part 1, women's ratings of men's commitment were lower than men's self-perceived commitment, and men's ratings of women's sexual intent exceeded women's self-perceived sexual intent. In Part 2, women's ratings of men's commitment underestimated each criterion measure of men's commitment, ${ }^{4}$ and men's ratings of women's sexual intent exceeded each criterion measure of women's sexual intent. In sum, as assessed relative to each type of criterion measure, men appear to overinfer women's sexual intent and women appear to underinfer men's commitment.

\section{Other Potential Mind-Reading Biases}

In contrast to these replicable effects, there was little evidence that men's inferences about women's commitment were erroneous. In Part 1, men's ratings did not differ significantly from the criterion measure. In Part 2, men's cross-sex perceptions fell between the two criterion measures, suggesting the possibility of reasonable accuracy.

There was little evidence that women's inferences about men's sexual intent were erroneous. In Part 1 of Study 2, women's perceptions exceeded men's self-perceived sexual intent. In Part 2 of Study 2, women's perceptions fell between the two criterion measures. The finding in Part 1 of Study 2 superficially seems at odds with the results of Study 1 and the results of past studies, which tend to document greater sexual perceptions of men relative to women. However, past studies have assessed women's perceptions of men's sexual intent relative to men's perceptions of men-not relative to men's self-perceived sexual intent as we have done in this study. ${ }^{5}$ The final results were the sibling effects, which are considered in the General Discussion.

\section{General Discussion}

\section{Women's Commitment Skepticism}

These studies document a new effect predicted by EMT. We hypothesized that women have commitment-reading adaptations biased toward underperceiving men's commitment. We hypothesized this psychological adaptation on the basis of the proposition that ancestral women suffered greater costs when they erred by falsely inferring a prospective mate's commitment. We confirmed this hypothesis. Women underperceived men's commitment as assessed relative to two criterion measures in two independent studies. In contrast, we found no consistent evidence that men misperceive women's commitment.

\section{Men's Sexual Overperception}

Using a minimal method with brief descriptions of cues, these studies replicated the sex differences in perceptions of sexual intent documented in previous studies (e.g., Abbey, 1982; Abbey \& Melby, 1986). We extended the past research by showing that men overestimate women's sexual intent as assessed relative to two criterion measures: women's perceptions of women and women's self-perceived sexual intent. Whereas past research focused

\footnotetext{
${ }^{3}$ An alternative explanation for men's more accurate reading of sisters' minds is familiarity - perhaps cross-sex siblings' minds are read more accurately because of the increased familiarity associated with living in the same household. To examine this hypothesis, we correlated the number of years that participants lived in the same household with their sibling (range: 4 to 21 years; $M=15.66, S D=3.09$ ) with the difference between participants' cross-sex and sibling perceptions. The difference between men's perceptions of women's sexual intent and their perceptions of their sisters' sexual intent was not significantly correlated with the number of years they lived in the same household (range of correlations with individual sexual-intent items was -.08 to $.05, p>.05$ ), nor was the difference between women's perceptions of their brothers and their perceptions of men significantly correlated with the number of years they lived with their brothers (range of correlations was -.01 to $.15, p s>.05$ ). On the basis of this particular measure of familiarity, there is little support for the familiarity hypothesis. This is an imperfect measure of familiarity, given that it is confounded with variables such as the time at which siblings move away from home, and other tests of this alternative explanation may be warranted.

${ }^{4}$ One reviewer suggested that the commitment avoidance items included in Study 2 may have primed an "uncommitted man" stereotype, which may have contaminated the results of each part of the study. In an independent sample the effects documented in Study 2 have been replicated using an instrument containing none of the potential priming items. Interested readers may contact the authors to obtain the replication results.

${ }^{5}$ The two exceptions are Abbey's original lab study (Abbey, 1982) and an independent replication (Saal et al., 1989). In these studies, selfperceptions and same-sex perceptions were collected; however, the crosssex perceptions were not compared with each of these potential criterion measures. The statistical analyses did not differentiate between these measures, and these studies therefore could not address the question of whether men's self-perception differed from women's perception of the men.
} 
specifically on whether men err in perceiving sexual intent, we also examined the accuracy of women's perceptions of sexual intent. In contrast to evidence of men's erroneous cross-sex perception, women's cross-sex perception of sexual intent falls between the two criterion measures of accuracy, suggesting that women may perceive men's sexual intent with reasonable accuracy.

In summary, the results of these studies suggest that men and women are biased mind readers. As predicted by EMT, men's and women's errors occur in different domains and in different directions. In the language of inferential statistics, men tend to make Type I errors in inferring women's sexual intent, and women tend to make Type II errors in inferring men's commitment.

\section{The Sister Effect}

Based on the adaptive-bias hypothesis, we predicted that men's sexual overperception would not occur when the target was their sister. This prediction was confirmed. Men's perceptions of their sisters' sexual intent were lower than their perceptions of other women's sexual intent. Moreover, men's perceptions of their sisters fell between the two criterion measures (women's perceptions of women and women's self-perceptions), suggesting that men may perceive their sisters' sexual intent fairly accurately.

In sharp contrast to men's correction for sisters, we found an opposite adjustment in women's perceptions of their brothers. Whereas women's perceptions of other men were between the two criterion measures, their perceptions of their brothers underestimated each criterion measure. We did not have an a priori hypothesis about women's perceptions of their brothers.

Our initial prediction of the sister effect was based on the hypothesis that men have evolved an adaptive bias to overinfer sexual interest only when forming inferences about a delimited group of women: those of reproductive age who are potential sexual partners. An alternative explanation, compatible with the current pattern of results, is that the sibling adjustments are driven by the well-known phenomenon whereby individuals tend not to think of their siblings sexually, perhaps as a product of incestavoidance mechanisms (e.g., Westemarck, 1921), and as a consequence see them as less sexually interested in others when observing cues such as a smile. Thus, more definitive tests of the adaptive-bias explanation will rest with studies that examine inferences about the sexual intent of other targets. According to the adaptive-bias explanation, for example, the overinference of sexual intent should not occur when men evaluate smiles and other cues from postmenopausal women or prepubescent girls-a prediction not made by the incest-avoidance hypothesis or other explanations unique to siblings.

\section{Limitations}

There are several important limitations of these studies. The first is the uncertainty of our criterion measures. We have argued that self-perceptions and same-sex perceptions may be biased in opposite directions, bracketing the true state of reality. We therefore view cross-sex perceptions that exceed or underestimate both of these criterion measures as possible errors. The specific pattern of the results we obtained-men's and women's errors in opposite directions in the hypothesized domains, but possible accuracy in other domains--is difficult to attribute to a systematic bias in our criterion measures alone. An alternative explanation for our findings based on criterion-measure bias would face the substantial burden of explaining why women's and men's criterion measures are biased in different directions only for the hypothesized effects.

A second important limitation is that the tests of our hypotheses involved hypothetical scenarios rather than real-life encounters. Men's sexual overperception has been reported by women in surveys of naturally occurring events (Abbey, 1987) and has been documented using a wide variety of methodologies, including laboratory studies of interactions between newly acquainted men and women, studies using photos and films as stimuli, and studies (such as the present studies) using hypothetical scenarios. Men's apparent error transcends the method used to study it. This crossmethod consistency corroborates the validity of using the hypothetical scenarios to study biases in interpersonal perception.

Ideally, the new effects we have documented-women's commitment underperception, the sibling effects, and the finding that men's self-perceived sexual intent is lower than women's perception of men's sexual intent-should be verified with the use of other methods, such as laboratory studies or other studies of live interactions. Pending explorations using other methods, it is worth noting that hypothetical scenarios are likely to reveal the default impressions that women and men have of the intentions of members of the opposite sex. Methods involving live interactions may reveal impressions that are affected by the somewhat idiosyncratic cues associated with particular interaction partners or particular settings. Default impressions of the opposite sex are important because they may be the starting points that anchor subsequently updated perceptions.

Future studies should also use the innovative methods of other accuracy researchers, such as the empathic accuracy method (Ickes, 1997), behavioral prediction methods (e.g., Levesque \& Kenny, 1993), and other methods (e.g., Aron, Aron, Tudor, \& Nelson, 1991; Sanitioso, Kunda, \& Fong, 1990). Replication with these methods would also be useful because they offer alternative criterion measures.

\section{Alternative Sexual Overperception Hypotheses}

The hypothesis proposed to account for men's overperception of women's sexual intent contrasts with three previous hypotheses: the general over-sexualization hypothesis, the media hypothesis, and the default-model hypothesis. The default model hypothesis, which proposed that men extend their self-perceptions to others, predicted that men should provide similar ratings for themselves, other men, and women. In Study 2, however, women's perception of men's sexual intent was significantly greater than men's selfperceived sexual intent and significantly lower than men's perceptions of other men's sexual intent, suggesting that men's self- and other perceptions are different. The oversexualization hypothesis and media hypothesis are challenged by the sister effect, which showed that men do not overperceive the sexual intent of all women. Men appear to correct their perceptions for their sisters.

One reviewer noted another possible explanation involving a socialized double-standard in American culture. According to this explanation, American society socializes men (and promotes stereotypes of men) to be interested in casual sex, whereas it socializes women (and promotes stereotypes of women) to be interested 
in commitment. Although it is undoubtedly true that men and women experience different socialization practices in the sexual domain (see, e.g., Low, 1989), we feel that this hypothesis and others like it are imprecise and lack the explanatory power to cogently account for the particular patterns of results, both from the current studies and the cumulative body of research findings. Nothing in the tenets of these alternative hypotheses predicts that men's and women's inferences will be biased in any direction. Why would men overinfer sexual interest in women just because they are socialized to be freer than women to pursue casual sex? In fact, using this same double-standard of socialization explanation, one might predict the opposite inferential bias on the part of men-that women tend not to be sexually interested-because they can plainly observe that women have been socialized to be sexually restricted. The key point is that nothing in the socialization and stereotype explanations or their variants appears to predict specific inferential biases, let alone particular patterns of inferential biases based on sex of actor and sex of target. These hypotheses tend to be sufficiently vague in their premises that they can be molded post hoc to explain any pattern of findings-bias in one direction, bias in the other direction, or no bias at all.

\section{Future Directions}

According to error management logic, varying the balance of false-positive and false-negative errors should cause shifts in the errors we have hypothesized. For ancestral men, for example, the costs of a missed sexual opportunity (false-negative error) would have been far lower, relative to the costs of failed pursuit (falsepositive error), if a target woman was pre- or postreproductive, as indicated by cues to youth, health, or attractiveness. EMT predicts that such women will not trigger sexual overperceptions.

EMT should also be tested in other domains of inference, such as inferences about sexual infidelity and inferences about aggressive intent. For men, the costs in compromised paternity of failing to detect cues to sexual infidelity may have been sufficiently large to create biased mind reading, causing men to err by inferring infidelity even where none exists (Buss, in press). Similarly, the ancestral costs of failing to correctly detect aggressive intentions, relative to the costs of being overcautious, may have created biased mind-reading adaptations, which lead men and women to overestimate the aggressive intentions of others.

\section{Error Management Theory and the Heuristics and Biases Approach}

In most imaginable circumstances, the best possible reasoning system is one that is always $100 \%$ accurate. This is impossible, however, when decisions are made under uncertain conditions. A cue used once to successfully predict an event may later fail. According to EMT, the criterion of good reasoning under such conditions is not overall or on-average correctness (also see Funder, 1987). Instead, optimal designs are sometimes those that result in errors that historically minimized overall costs or maximized overall benefits. This rule of good design contrasts with the nearly ubiquitous assumption in psychology that optimal reasoning systems are those that best correspond to normative rules or that best produce veridical inferences.
In the heuristics and biases approach, the optimal accuracy assumption has been made explicit. In introducing the approach, Kahneman et al. (1982) lauded the influence of Bayes's theorem in psychology because it offered " a fully articulated model of optimal performance" (p. xi). Later, in summarizing the empirical harvest generated by the approach, Shafir and Tversky (1995) explained the difference between the "normative approach," which describes the "rational decision maker," and the "descriptive approach," which describes how "decisions are actually made" (p. 77). The assumed optimality of accuracy is also evident in the labels heuristics-and-biases researchers apply to reasoning effects that deviate from normative standards. Such deviations are called "illusions," "sins" (Piatelli-Palmarini, 1994), and "fallacies" (Tversky \& Kahneman, 1974), and are described as "ludicrous" and "indefensible" (Tversky \& Kahneman, 1971).

The view that evolved psychological mechanisms may be designed to be biased has an important implication for the interpretation of errors. Heuristics and biases researches have assumed that because cognitive capacity and information processing time are limited, systematic errors reveal information-processing shortcuts (Kahneman et al., 1982; Kahneman \& Tversky, 1996; Tversky \& Kahneman, 1974). This interpretation of errors appears to be the most common interpretation of errors in judgment and decision making (e.g., Lopes, 1991; Osherson, 1995). EMT, in contrast, proposes that some errors reveal the cost and benefit asymmetries present over evolutionary history. Errors may be evidence of evolved adaptive biases, not simplifying heuristics.

\section{Conclusions}

Errors have intrigued psychologists because they help to reveal the underlying design of the mind. They also point out human fallibility--something many psychologists endeavor to correct. The explanations for reasoning errors, however, remain in dispute (Cosmides \& Tooby, 1996; Gigerenzer, 1996; Kahneman \& Tversky, 1996). We offer an interpretation of errors that contrasts with the dominant interpretation of cognitive errors in psychology. Error management theory explains men's sexual overperception, predicts a new mind-reading error made by women, and predicts a case in which men's sexual overperception is corrected. We know of no alternative theory that would have predicted this specific pattern of results.

An important implication of error management theory is that many reasoning mechanisms are not designed to be maximally correct. This insight may alter the interpretation of known cognitive errors and may lead to the discovery of new cognitive errors. We have suggested several avenues for testing error management theory in domains such as inferences about infidelity and aggressive intent. Ultimately, these tests will determine the usefulness of error management theory as a broader model of error and bias in reasoning.

\section{References}

Abbey, A. (1982). Sex differences in attributions for friendly behavior: Do males misperceive females' friendliness? Journal of Personality and Social Psychology, 42, 830-838.

Abbey, A. (1987). Misperceptions of friendly behavior as sexual interest: A survey of naturally occurring instances. Psychology of Women Quarterly, 11, 173-194. 
Abbey, A. (1991). Misperception as an antecedent of acquaintance rape: A consequence of ambiguity in communication between men and women. In A. Parrot \& L. Bechhofer (Eds.), Acquaintance rape: The hidden crime (pp. 96-111). New York: Wiley.

Abbey, A., \& Hamish, R. J. (1995). Perception of sexual intent: The role of gender, alcohol consumption, and rape supportive attitudes. Sex Roles, 32, 297-313.

Abbey, A., \& Melby, C. (1986). The effects of nonverbal cues on gender differences in perceptions of sexual intent. Sex Roles, 15, 283-289.

Aron, A., Aron, E. N., Tudor, M., \& Nelson, G. (1991). Close relationships as including other in the self. Joumal of Personality and Social Psychology, 60, 241-253.

Betzig, L. (1989). Causes of conjugal dissolution. Current Anthropolagy, 30, 654-676.

Buss, D. M. (1994). The evolution of desire: Strategies of human mating. New York: Basic Books.

Buss, D. M. (in press). The dangerous passion: Why jealousy is as necessary as love and sex. New York: Free Press.

Buss, D. M., \& Dedden, L. A. (1990), Derogation of competitors. Journal of Social and Personal Relationships, 7; 395-422.

Cosmides, L., \& Tooby, J. (1996). Are humans good intuitive statisticians after all? Rethinking some conclusions from the literature on judgment under uncertainty. Cognition, 58, 1-73.

Dawkins, R. (1989). The selfish gene (2nd ed.). Oxford, England: Oxford University Press.

Einon, D. (1994). Are men more promiscuous than women? Ethology and Sociobiology, 15, 131-143.

Funder, D. C. (1987). Errors and mistakes: Evaluating the accuracy of social judgment. Psychological Bulletin, 101, 75-90.

Gigerenzer, G. (1996). On narrow norms and vague heuristics: A reply to Kahneman and Tversky (1996). Psychological Review, 103, 592-596.

Green, D. M., \& Swets, J. A. (1966). Signal detection and psychophysics. New York: Wiley,

Hamilton, W. D. (1964). The genetical evolution of sacial behavior. Journal of Theoretical Biology, 7, 1-52.

Haselton, M. G., Buss, D. M., \& DeKay, W. T. (1998, July). A theory of errors in cross-sex mindreading. Paper presented at the Human Behavior and Evolution Society Meeting, Davis, CA.

Hurtado, A. M., \& Hill, K. R. (1992). Paternal effect on offspring survivorship among Ache and Hiwi hunter-gatherers. In B. S. Hewlett et al. (Eds.), Father-child relations: Cultural and biosocial contexts (pp. 31-55). New York: Aldine de Gruyter.

Ickes, W. (1997). Emputhic accuracy. New York: Guilford Press.

Jankowiak, W. (Ed.). (1995). Romantic passion: A universal experience? New York: Columbia University Press.

Johnson, C. B., Stockdale, M. S., \& Saal, F. E. (1991). Persistence of men's misperceptions of friendly cues across a variety of interpersonal encounters. Psychology of Women Quarterly, 15, 463-475.

Kahneman, D., Slovic, P., \& Tversky, A. (1982). Judgment under uncertainty: Heuristics and biases. New York: Cambridge University Press.

Kahneman, D., \& Tversky, A. (1996). On the reality of cognitive illusions. Psychological Review, 103, 582-591.

Levesque, M. L., \& Kenny, D. A. (1993). Accuracy of behavioral predictions at zero acquaintance: A social relations analysis. Journal of Personality and Social Psychology, 65, 1178-1187.

Lopes, L. (1991). The rhetoric of irrationality. Theory and Psychology, 1, $65-82$.
Low, B. S. (1989). Cross-cultural patterns in the training of children: An evolutionary perspective. Journal of Comparative Psychology, 103, 313-319.

Marks, G., \& Miller, N. (1987). Ten years of research on the falseconsensus effect: An empirical and theoretical review. Psychological Bulletin, 102, 72-90.

Nesse, R. M., \& Williams, G. C. (1998). Evolution and the origins of disease. Scientific American, 11, 86-93.

Nisbett, R. E., \& Ross, L. (1980). Human inference: Strategies and shortcomings of social judgment. Englewood Cliffs, NJ: Prentice Hall.

Osherson, D. N. (1995). Probability judgment. In E. E. Smith \& D. N. Osherson (Eds.), Thinking: An invitation to cognitive science (2nd ed., Vol. 3, pp. 35-75), Cambridge, MA: MTT Press.

Piatelli-Palmarini, M. (1994). Inevitable illusions. New York: Wiley.

Saal, F. E., Johnson, C. B., \& Weber, N. (1989). Friendly or sexy? It may depend on whom you ask. Psychology of Women Quarterly, 13, 263276.

Sanitioso, R., Kunda, Z., \& Fong, G. T. (1990). Motivated recruitment of autobiographical memories. Journal of Personality and Social Psychol. ogy, 59. 229-241.

Schlager, D. (1995). Evolutionary perspectives on paranoid disorder. Delusional Disorders, 18, 263-279.

Schmitt, D. P., \& Buss, D. M. (1996). Strategic self-promotion and competitor derogation: Sex and context effects on the perceived effectiveness of mate attraction tactics. Journal of Personality and Social $P_{s y-}$ chology, 70, 1185-1204.

Searcy, W. A., \& Brenowitz, E. A. (1988, March 10). Sex differences in species recognition of avian song. Nature, 332, 152-154.

Sedikides, C. (1993). Assessment, enhancement, and verification determinants of the self-evaluation process. Journal of Personality and Social Psychology, 65, 317-338.

Shafir, E., \& Tversky, A. (1995). Decision making. In E. E. Smith \& D. N. Osherson (Eds.), Thinking: An invitation to cognitive science (2nd ed., Vol. 3, pp. 77-100). Cambridge, MA: MTT Press.

Shotland, R. L., \& Craig, J. M. (1988). Can men and women differentiate between friendly and sexually interested behavior? Social Psychology Quarterly, 51, 66-73.

Symons, D. (1979). The evolution of human sexuality. New York: Oxford University Press.

Tomarken, A. J., Mineka, S., \& Cook, M. (1989). Fear-relevant selective associations and covariation bias. Journal of Abnormal Psychology, 98 381-394.

Tversky, A., \& Kahneman, D. (1971). Belief in the law of small numbers. Psychological Bulletin, 76, 105-110.

Tversky, A., \& Kahneman, D. (1974, September 27). Judgment under uncertainty: Heuristics and biases. Science, 185, 1124-1131.

Westermarck, E. (1921). The history of human marriage. London: Macmillan.

Received December 1, 1998 Revision received June 2, 1999 Accepted July 22, 1999 